\title{
An Assessment of Dentist's Attitudes to the Shortened Dental Arch Concept
}

\author{
Ghazala Suleman $^{1}$, Saurabh Chaturvedi ${ }^{1 *}$, Rania A. Shareef ${ }^{1}$, Asim Elsir Elmahdi ${ }^{1}$, Mohamed Fadul A. Elagib $^{2}$ \\ ${ }^{1}$ Department of Prosthetic Dentistry, College of Dentistry, King Khalid University, Abha, Saudi Arabia; ${ }^{2}$ Department of \\ Periodontics Dentistry, College of Dentistry, King Khalid University, Abha, Saudi Arabia
}

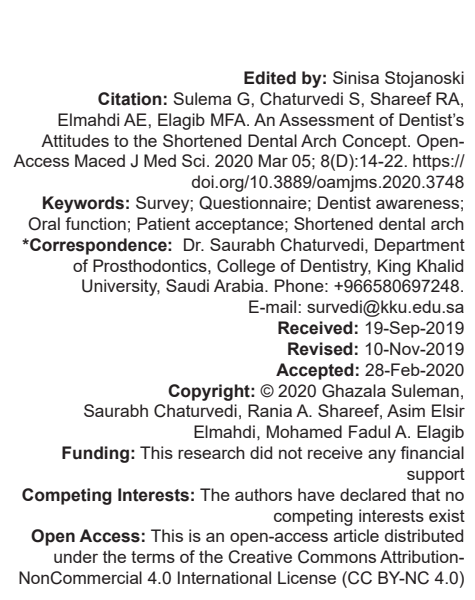

Introduction

The complete dental arch rehabilitation is a traditional concept to sustain proper functional occlusion and an esthetically acceptable appearance [1], [2]. Until now, it has not been possible to define the minimum number of teeth necessary to fulfill the functional demands of an individual since this varies individually and is associated with the patient's age. There are many factors to be considered while deciding how many teeth to save and restore to guarantee satisfactory oral function, such as patient preferences, the aim of the dental services, and the efficiency of treatment procedures [3], [4], [5], [6].

The shortened dental arch (SDA) is defined as a specific type of dentition with an intact anterior region and a reduction in the occluding pairs of posterior teeth, starting posteriorly [4], [7], [8], [9]. This was first described by the Kayser et al. at the Dental School of the University of Nijmegen, the Netherlands, in 1981 [8].

"Retention of a healthy, natural, functioning dentition comprising not $<20$ teeth and not requiring a prosthesis" isthe goal for oral health given by the
WHO in 1992 [10], [11]. This goal is achieved by the "Shortened Dental Arch concept." It is characterized by a minimum of four occlusal units that provide functional satisfaction to older adults with sufficient adaptive capacity. This is a conservative approach that aims to preserve the strategic part of the dental arch and to reduce unnecessary complex restorative procedures, time, and cost to the patient [12], [13].

SDA can be extended by a free end removable partial denture, a cantilever fixed partial denture or an implant-supported prosthesis. However, studies have revealed that the free end removable partial denture role is dubious [14], [15], [16], a cantilever fixed partial denture (FDP) creates stress on the abutment and has many technical complications [1], [10], and implants are not always possible due to their risky posterior site [10], [17].

The selection of treatment for replacement of missing teeth is mostly governed by attitudes and the knowledge of the dentist, and it would be expected to play a key role in dentistry. Social-psychology theory describes attitudes as having at least two interdependent components: Cognitive perceptions (the way the facts are understood) and affective emotions (the way one feels about the facts) [18]. Attitudes 
should be integrated as anecdotal components when considering prosthodontic decision-making among general practitioners [19]. Supplementary studies have shown an association between attitudes and clinical behavior.

There are a few reports in the literature that state the attitudes of dental clinicians toward the SDA concept [4], [9], [20], [21], [22]. In general, prosthodontists and practitioners with special interests in prosthodontics are considered to have a positive attitude toward the SDA concept; on the other hand, it has also been revealed that this concept is not widely practiced [9], [20], [21]. Little is known related to the attitudes and acceptance of the SDA concept in prosthodontic treatment planning among dentists. Furthermore, studies regarding the SDA concept in Saudi Arabia are few, and until now, no study has been conducted in our Aseer region. This is a region of Saudi Arabia located in the southwest of the country that is named after the Asīr tribe. It has an area of $76,693 \mathrm{~km}^{2}$ and an estimated population of 1,913,392. The capital of the Aseer Region is Abha. Being one of the important regions of Saudi Arabia, it is important to assess the concept of SDA among the dentists working here, and so this study was planned with the aim of assessing dentists' attitudes toward the SDA concept in the Aseer region, Saudi Arabia, and related objectives were to determine the dentists' knowledge and perceptions about SDA and the application of it in their clinical practice. The null hypothesis formulated was that the attitude of dentists toward the SDA concept would be negative and that dentists would not be aware of the SDA concept in this region.

\section{Materials and Methods}

The current research was an observational cross-sectional type of study where the data were collected from the representative population at a specific time interval of 3 months from December 1,2017 , to February 28,2018 . It was undertaken to measure dentists' attitudes toward the SDA concept. A quota sampling (non-probability sampling) technique was used. In Aseer Region, a total of 98 licensed dentists (a/c to Saudi Commission for Health Specialties [SCFHS] database) and 112 King Khalid University Staff were working. In that, 204 dentists, working as academicians or clinicians or both, in the Aseer region were participants. The chief researcher, along with the coresearchers, collected the data.

\section{Ethical considerations}

This study was conducted in compliance with the protocol; ethical approval was obtained from the ethical committee of King Khalid University, College of Dentistry (Ethical Approval Number - SRC/ETH/201718/020). The subjects participating in the present study provided their informed written consent before taking the survey by signing the consent form attached to the questionnaire (Appendix 1). Participation was on a voluntary basis, and there were no incentives. Data protection and anonymity were guaranteed.

\section{Questionnaire}

General information about the SDA concept was included in the questionnaire. The questionnaire designed for this study was based on a modified model adopted from a study by Witter et al. [9] It was attached with a short explanation of the SDA concept. The study was carried out with the help of 17 wellstructured questionnaires. The questionnaire's validity and reliability were evaluated by four prosthodontists and a psychometrician for vetting and remarks. The recommended modifications were implemented to ensure its cogency. Furthermore, the questionnaire was validated by doing a pilot study on 45 participants. After analyzing the dataset, consistent responses were noticed, which depicted high internal consistency for the questionnaire, with a Cronbach's Alpha value of 0.74 . The questionnaire used in the study consisted of two parts. The first part included the dentists' demographic data, and the second part consisted of the questions regarding the SDA concept. This section involved 14 questions related to the dentists' knowledge, attitude, practicerelated questions and opinion regarding specific factors influencing decision-making for SDA patients, namely, knowledge (question numbers 5, 6, and 7), attitude (question numbers $8,14,15$, and 18), and practicerelated questions $(9,10,11,12,13,16$, and 17). The respondents had to answer them using a 5-point Likert scale (question numbers 7 and 15).

These questionnaires were given personally to the participants. Each participant's communication data were collected and coded. At an interval of every 1 week for 2 times, all participants were reminded to return the questionnaire forms with their responses. If necessary, an essential detailed conversation was conducted with the respondents, and clarification was provided regarding the study and its goals.

\section{Statistical analysis}

To achieve the outlined objectives, the scores were calculated based on the responses given by the participants. A single investigator analyzed all returned questionnaires. A database was constructed using Microsoft Excel (Microsoft, Redmond, WA) and imported into the Statistical Package for the Social Sciences (SPSS) version 20 (Chicago, Illinois, USA) for statistical analysis. Descriptive statistical analysis, which included frequencies and percentages, was used to characterize 
the data and report the diversity of the sample employed in this research. Association with the factors was tested for significance using Chi-square tests, and $p<0.05$ was considered statistically significant. The opinions with abnormally high proportions and relatively higher knowledge levels were evaluated by the control chart technique. Bar graphs, multiple bar graphs, pie charts, etc., were constructed to visualize various summaries of the data and findings.

\section{Results}

Out of 204 participants, 174 gave their responses. Thus, the total response rate was $85.29 \%$. Among the 174 respondents, most were males (69.5\%) and qualified as postgraduates (55.7\%), 46.6\% had 1-5 years of experience, $23.0 \%$ had 5-10 years of experience, and the remaining $30.5 \%$ had more than 10 years of experience (Table 1 ).

Table 1: Distribution of subjects among the study groups according to biosocial characteristics

\begin{tabular}{llll}
\hline Variable & Category & \multicolumn{2}{l}{ Total $(\mathbf{n}=\mathbf{1 7 4})$} \\
\cline { 3 - 4 } & & $\mathbf{n}$ & $\mathbf{\%}$ \\
\hline Gender & Male & 121 & 69.5 \\
Qualification & Female & 53 & 30.5 \\
& Graduate & 77 & 44.3 \\
Years of experience & Postgraduate & 97 & 55.7 \\
& 1-5 years & 81 & 46.6 \\
Career prospective & 5-10 years & 40 & 23.0 \\
& More than 10 years & 53 & 30.5 \\
& Academician & 41 & 23.6 \\
& Clinician & 63 & 36.2 \\
& Both & 70 & 40.2 \\
\hline
\end{tabular}

Among the surveyed dentists, $43.7 \%$ were aware of the SDA concept. Therefore, the expected awareness about the SDA concept among the dentists was in the range of $36.31-51.05 \%$ with $95 \%$ confidence. The assessment of knowledge of the SDA concept was evaluated between various combinations on the basis of biosocial characteristics. Between male and female respondents, no significant difference in awareness of SDA was found ( $p=0.296)$, but on the basis of qualifications and years of experience, a highly significant difference was noted. Dentists holding postgraduate qualifications indicated more awareness $(93 \%)$ than those with only a basic dental degree (19.5\%) (Table 2).

In Table 3, it is very clear that participants opted for SDA for various clinical situations such as a good long-term prognosis $(86.8 \%)$, age greater than 50 years $(78.9 \%)$, and financial limitations to dental care $(79.0 \%)$. Most of the respondents also agreed that the SDA approach is acceptable in clinical practice and that it is simple and more cost-effective (Table 3).

Regarding concerns about attitudes toward SDA application, among the respondents who were familiar with the SDA concept, only $2.6 \%$ were applying
Table 2: Association of knowledge about SDA with biosocial characteristics

\begin{tabular}{|c|c|c|c|c|c|c|}
\hline \multirow[t]{2}{*}{ Variable } & \multirow[t]{2}{*}{ Category } & & \multicolumn{2}{|c|}{$\begin{array}{l}\text { Knowledge } \\
\text { about SDA }\end{array}$} & \multirow[t]{2}{*}{ Chi-square } & \multirow[t]{2}{*}{ p-value } \\
\hline & & & Yes & No & & \\
\hline \multirow[t]{2}{*}{ Gender } & Male & $\begin{array}{l}\mathrm{n} \\
\%\end{array}$ & $\begin{array}{l}56 \\
46.3\end{array}$ & $\begin{array}{l}65 \\
53.7\end{array}$ & 1.094 & 0.296 \\
\hline & Female & $\begin{array}{l}\mathrm{n} \\
\%\end{array}$ & $\begin{array}{l}20 \\
37.7\end{array}$ & $\begin{array}{l}33 \\
62.3\end{array}$ & & \\
\hline \multirow{2}{*}{ Qualification } & Postgraduate & $\mathrm{n}$ & 61 & 36 & & \\
\hline & & $\%$ & 62.9 & 37.1 & & \\
\hline \multirow{5}{*}{$\begin{array}{l}\text { Years of } \\
\text { experience }\end{array}$} & $1-5$ years & $\mathrm{n}$ & 21 & 60 & 21.797 & $<0.001$ \\
\hline & & $\%$ & 25.9 & 74.1 & & \\
\hline & $5-10$ years & $\mathrm{n}$ & 20 & 20 & & \\
\hline & & $\%$ & 50.0 & 50.0 & & \\
\hline & $\begin{array}{l}\text { More than } 10 \\
\text { years }\end{array}$ & $\begin{array}{l}\mathrm{n} \\
\%\end{array}$ & $\begin{array}{l}35 \\
66.0\end{array}$ & $\begin{array}{l}18 \\
34.0\end{array}$ & & \\
\hline \multirow[t]{5}{*}{$\begin{array}{l}\text { Career } \\
\text { prospective }\end{array}$} & Academician & $\begin{array}{l}\mathrm{n} \\
\%\end{array}$ & $\begin{array}{l}30 \\
73.2\end{array}$ & $\begin{array}{l}11 \\
26.8\end{array}$ & 45.781 & $<0.001$ \\
\hline & Clinician & $\mathrm{n}$ & 7 & 56 & & \\
\hline & & $\%$ & 11.1 & 88.9 & & \\
\hline & Both & $\mathrm{n}$ & 39 & 31 & & \\
\hline & & $\%$ & 55.7 & 44.3 & & \\
\hline Total & & & 76 & 98 & & \\
\hline
\end{tabular}

it very frequently, $21.1 \%$ were applying it regularly, and $36.8 \%$ were applying it occasionally. However, $39.5 \%$ of respondents never applied it (Figure 1). Many dentists $(43 \%)$ responded that their patients had objections initially to the SDA treatment concept, and more than $30 \%$ revealed that their patients had no idea about the SDA concept at all.

Table 3: Clinical situations most apt to propose SDA

\begin{tabular}{llll}
\hline Reason & Opinion & $\mathbf{n}$ & $\%$ \\
\hline Age $(>50$ years $)$ & Strongly agree & 33 & 43.4 \\
& Agree & 27 & 35.5 \\
Good long-term prognosis & Not sure & 18 & 23.7 \\
& Strongly agree & 28 & 36.8 \\
& Agree & 38 & 50.0 \\
Progressive caries and periodontal disease & Not sure & 10 & 13.2 \\
& Strongly agree & 22 & 28.9 \\
& Agree & 36 & 47.4 \\
& Not sure & 14 & 18.4 \\
Financial limitations to dental care & Disagree & 4 & 5.3 \\
& Strongly agree & 16 & 21.1 \\
& Agree & 44 & 57.9 \\
& Not sure & 13 & 17.1 \\
Other limitations to dental care & Disagree & 3 & 3.9 \\
& Strongly agree & 15 & 19.7 \\
& Agree & 35 & 46.1 \\
Sound maxillomandibular jaw relationship & Not sure & 23 & 30.3 \\
& Disagree & 3 & 3.9 \\
& Strongly agree & 15 & 19.7 \\
& Agree & 46 & 60.5 \\
& Not sure & 13 & 17.1 \\
Absence of any oral pathological manifestations & Disagree & 2 & 2.6 \\
& Strongly agree & 19 & 25.0 \\
& Agree & 35 & 46.1 \\
& Not sure & 20 & 26.3 \\
& Disagree & 2 & 2.6 \\
\hline
\end{tabular}

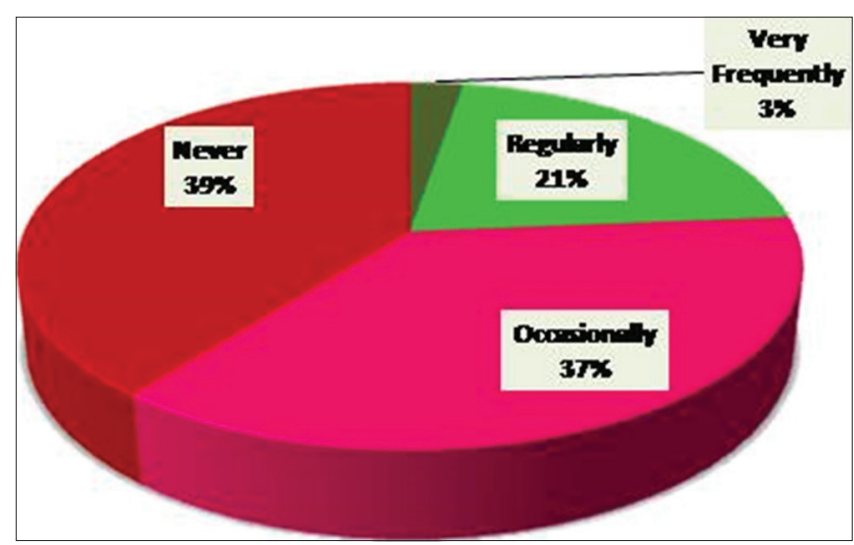

Figure 1: Frequency of applying the SDA concept 
In the studied population of dentists, $31.6 \%$ affirmed that there is a need for further treatment after SDA, and $29.7 \%$ affirmed that there is a change in masticatory efficiency with the SDA. A total of $25.7 \%$ supposed that the SDA leads to temporomandibular joint (TMJ)-associated issues, while $38.9 \%$ had the opinion that the cost of treatment generally influences the patients' acceptance of SDA [22], [36]. According to $55.4 \%$ of respondents, the SDA concept has a useful place in clinical practice. The dentists pointed out that the chief reason to provide prostheses to replace missing first, second, and/or third molars were to improve masticatory function, which was supported by $84.5 \%$ of respondents (Table 4 ). The next most common

Table 4: Reasons for providing prostheses to replace missing first, second, and/or third molars

\begin{tabular}{lll}
\hline Reasons for replacement & $\mathbf{n}$ & $\%$ \\
\hline Restore posterior support & 125 & 71.8 \\
Prevention of anterior wear & 69 & 39.7 \\
Improved masticatory function & 147 & 84.5 \\
Patient's desire & 58 & 33.3 \\
Maintain health of TMJs & 112 & 64.4 \\
Esthetics & 27 & 15.5 \\
Others & 5 & 2.9 \\
Total & 174 & 100.0 \\
\hline TMJ: Temporomandibular joint & &
\end{tabular}

chief reason was the restoration of posterior support and maintenance of healthy TMJ that was supported by $71.8 \%$ and $64.4 \%$ of respondents, respectively.

\section{Discussion}

It has been a dominant quest of dental researchers since the beginning of the modern era to determine the minimum number of teeth that are adequate for efficient functional occlusion, mastication, esthetics, and phonetics and, eventually, for a decent quality of life for the patient [23], [24]. Although this is highly subjective in nature, in the literature, it is documented and proven that SDA provides a satisfying oral function and offers advantages such as enhanced oral hygiene, comfort, and lower financial expenditure, signifying this concept as a treatment option [4], [24], [25], [26].

The knowledge and attitude of the dentist are of utmost importance in deciding the treatment plan. Therefore, this study was conducted to assess the dentist's attitude toward the SDA concept. The results of the study showed a positive attitude of dentists toward SDA; thus, the null hypothesis was rejected, and similar results have been reported in the previous studies [8], [9], [21]. This supports the fact that the SDA concept has a useful place in clinical practice.

The present study was conducted in the Aseer region, and a response rate of more than $85 \%$ was noted, which was high compared with previously reported comparable studies between $54 \%$ and $82 \%$ [8], [9], [20], [22], [27]. The high response rate may be because the questionnaire was distributed and collected personally, participants were reminded twice to return it, and a sufficient response period, namely, 2 weeks, was given to allow participants to answer and return the questionnaire.

Demographic data showed that male dentists were more than double in number relative to their female counterparts, demarcating the need for more female dentists in this area. Young dentists with 1-5 years of experience made up $46.6 \%$, and those with postgraduate qualification made up $50 \%$ of the population and were willing to achieve a career as an academician and clinician (Table 1). Thus, enhancement of awareness and acceptance of the SDA concept could be easy, and it could grow exponentially. These young dentists when given details about SDA at this stage will be utilizing this concept often, and with experience, the level of awareness will increase.

A correct and specific description of SDA can be given by a dentist only when he/she has adequate knowledge about SDA. In the present study, the academicians had a high awareness level of SDA, $73.2 \%$, compared to clinicians at $11.1 \%$, which can be seen in relation to their qualification level, as in academics, postgraduate studies are compulsory. Among the respondents, only $43.7 \%$ of dentists were aware of the SDA concept, similar to $34.4 \%$ [28], $40 \%$ [29], and $61 \%$ [30] in other studies. This low level of awareness may be due to the fact that the SDA concept is still not well known as a problem-oriented approach and as a viable treatment option [22]. Awareness about SDA was enhanced with a higher qualification, as noted in our study, which is similar to the results of the previous studies [31]. Knowledge about SDA also increases as the years of experience increase, which is in accordance with the previous studies [30]. In our study, in respondents with more than 10 years of experience, the awareness level of SDA was $66.0 \%$, highest among those with 5 years and 5-10 years of experience. These results show that there is a need for enhancing the amount and level of information in the BDS program, and methods should be adopted to train the clinicians in short and effective ways in relation to the SDA concept. If the information will be provided at the basic level, the understanding will become clearer, and with experience, dentists will develop expertise in SDA treatment, as seen in our study where years of experience increase acquaintance and acceptance toward SDA.

In our study, postgraduate studies were the chief source of knowledge about SDA, underlined by the maximum number of respondents $(52.6 \%)$, followed by continuous dental education programs $(21.1 \%)$ and undergraduate studies (18.4\%). These three sources of knowledge were reported at frequencies above or equal to the average (18.9\%). This highlights the fact that CDE programs are the most effective way to enhance the knowledge of SDA among dentists since 
not all dentists go for postgraduate studies, for which the reasons may be many, but through CDE programs, the information can be provided to them in a simple, effective, and easy manner.

There are various clinical situations described in the literature where SDA can be opted for as a superior treatment option. The dentist should have a positive attitude and favorable perception of it to apply it in that particular situation. In our study, similar to the previous studies [22], [30], [32], participants showed positive attitudes toward SDA in various clinical situations, as shown in Table 3 . This result supports the fact that the ultimate success of the treatment is determined by a good long-term prognosis. In the SDA concept, the overall prognosis remains good as it maintains the dentition in a stabilized functional manner with proper distribution of the occlusal forces.

Even though SDA is based on conservative treatment concepts and healthy maintenance of existing dentition, the situation revealed in the present study should raise major concerns since those dentists who know about SDA still do not apply it. This may be due to their insufficient knowledge about SDA, low financial benefit, or due to poor patient acceptance. A low SDA application rate has also been shown in former studies [28], [33]. The proportion of participants who applied the SDA concept in this study was generally much lower than that reported in studies by Witter et al. (93\%) [8], Sarita et al. (31\%) [22], Kumar and George (79\%) [27], and Abuzar et al. (82\%) [30]. The only exception is a study by Arigbede et al. [34] in Nigeria in 2009 in which fewer than $5 \%$ of dentists had applied the SDA concept clinically. Moreover, studies conducted in Tanzania [22] and Nigeria [34] found that most participants doubt SDA implementation in clinical practice. These findings suggest that dentists in developing countries tend to lack experience with the application of the SDA concept compared with those in developed countries.

Similar to dentists, patients' reactions in response to SDA matter a lot for its application in routine clinical practice. In our study, almost half of the dentists said that initially, their patients had objections but agreed after explanations regarding the shortening of his/her dental arch for the treatment purpose. These findings are similar to the study conducted by Kumar et al. [27] in 2010 and Gupta [31] in 2016, where it was found that $57 \%$ and $38.1 \%$, respectively, of the patients, either had no objection or initially objected to SDA but later agreed following a detailed explanation [19], [22]. However, there was a large percentage of patients, $31.6 \%(-32 \%)$, who were unaware of the SDA concept (Figure 2). Such patients require special attention because by explaining to them properly about SDA, they may feel positively about SDA. This was substantiated by $13.2 \%$ of patients who did not raise any objection after a satisfactory explanation, similar to the study by Sarita et al. [22].

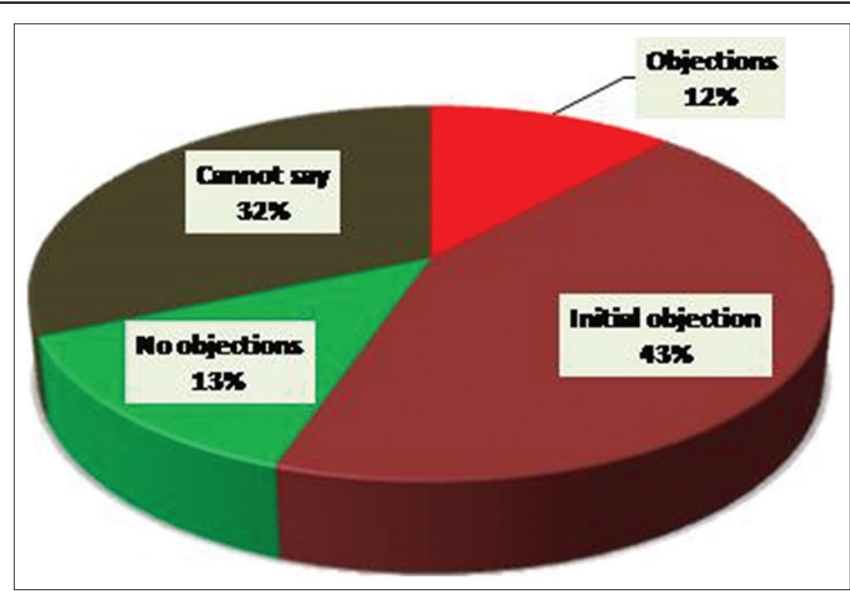

Figure 2: Patient reaction to applying SDA concept

The dentist's perception of SDA becomes more important as it basically reflects the level of SDA understanding that dentists have (Figure 3). Perception is something that represents an individual's own view or interpretation of something. While looking at the responses, it was found that many participants in the concerned area were of the view that there is a need for further treatment, masticatory efficiency will change, and the patient might suffer from TMJ-associated issues. Around $38.9 \%$ had the opinion that the cost of treatment generally influences the patient's acceptance of SDA [22], [35].

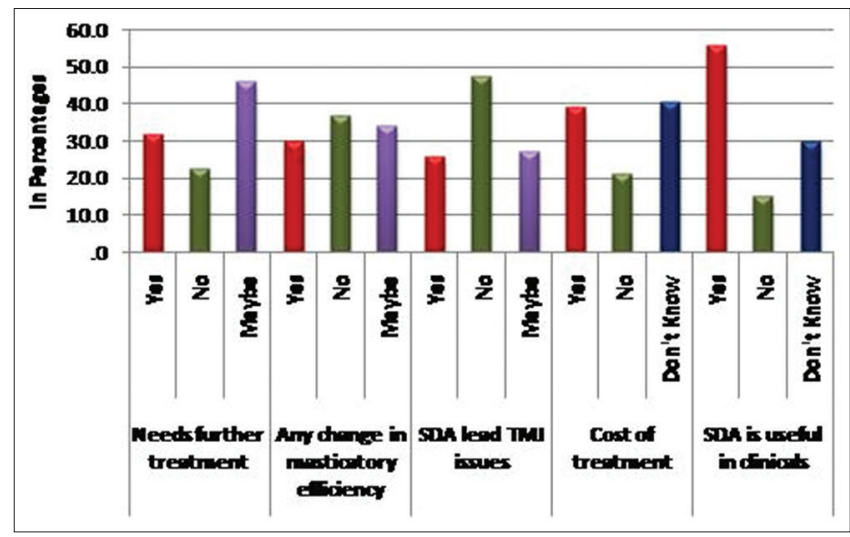

Figure 3: Dentist perception about SDA concept

However, more than half of the respondents agreed that the SDA concept has a useful place in clinical practice. Overall, the results resemble the findings of similar studies [31], [25], [27], [36], [37], where the dentists' perception was generally against the use of SDA. Even though the dentist had a positive attitude and a satisfactory understanding, due to incomplete understanding, the SDA treatment was not selected, and patients were not motivated about it. This was more obvious in the responses to the statement, "All missing molar teeth should be replaced in all patients," where more than $65 \%$ of the respondents either agreed or do not know, while only $31.6 \%$ disagreed. This is alarming as it is not always possible nor required to replace all missing molars. It may be affected by serious reasons such as the systemic condition of the patient, bone loss, insufficient abutment, cost, uncertain anatomical features, and many others. 
After looking at the opinions about the reasons to provide prostheses to replace missing first, second, and/or third molars, it was found that the chief reason was improved masticatory function followed by restoration of posterior support and maintenance of a healthy TMJ, which was similar to previous studies where the responses to the same questions were $77.7 \%, 78.3 \%$, and $37.15 \%$, respectively [30]. The SDA concept also supports the same. It is documented that the main occlusal table is associated with the premolar and first molar. The maximum amount of masticatory functions occurs in this section. In SDA treatment up to the first molar, the teeth are replaced, thus providing good chewing units to the individuals along with good esthetics. Witter et al. [8] stated that just to replace all teeth for rehabilitation purposes is not clinically proficient since SDA fulfills all of the requirements for satisfactory functional occlusion, provides sufficient oral comfort in terms of chewing ability and dental appearance, has sufficient mandibular stability to prevent signs and symptoms of mandibular dysfunction, and is thus a healthy stomatognatic system, and both the dentist and patient should choose it wisely. Basic knowledge of SDA is important for all dentists, so they can consider a simpler treatment plan for selected patients, if applicable, rather than trying to restore the occlusion of the whole dental arch, which is more complex, timeconsuming, and expensive [32].

In this study, most dentists replaced molars with distal extension partial dentures in subjects with SDA $(62.6 \%)$, similar to a former study [31]. The role of RPD in oral comfort and oral function may be questioned, and its role is dubious [14], [15], [16]. Studies have shown that a cantilever FPD creates considerable compressive stress on the abutment, and technical complications such as deboning and a substantial amount of extra chair time may be needed [1], [10]. Implant treatment is not always possible due to a risky posterior site, inadequate bone support, and the cost of the treatment [10], [17]. Thus, overall, it could be noted that SDA is beneficial [4], [23], [26] in a sense since it is a simplification of extensive restorative management, requires easier maintenance (subsequent to the SDA) for both the patient and the dentist, includes simplified oral hygiene maintenance, and has a good prognosis for the remaining teeth if the patient learns to maintain his/her own dentition.

\section{Recommendations}

Through the results of this study, it is recommended that the SDA concept should be added in detail to undergraduate studies, frequent CDE programs should be conducted to enhance knowledge about SDA, and patients should be informed and motivated toward SDA so that cost-effective, easy, and efficient treatment can be provided in indicated cases.

\section{Limitations}

The limitations of the study are its limited sample size (174) and limited area. It will be better to collaborate with government agencies to cover the entire kingdom of Saudi Arabia so that the full scenario can be determined regarding SDA among dentists.

\section{Conclusions}

It was determined in the present study that most dentists are still unacquainted with the SDA concept, especially those with no postgraduate studies. In general, dentists have a positive attitude, but due to incomplete understanding, the SDA concept is still unpopular. There is an urgent need to increase awareness of this concept as it is the most conservative, simple, and cost-effective approach to treat partially dentate older patients. This can be achieved by the inclusion of the SDA concept in the undergraduate curriculum in a coordinated manner and by continuous dental education programs.

\section{References}

1. Jepson NJ, Allen PF. Short and sticky options in the treatment of the partially dentate patient. Br Dent J. 1999;187(12):646-52. https://doi.org/10.1038/sj.bdj.4800357a

PMid:10654439

2. Encarnação IC, Molina IC, Luna M, Cardoso AC. Reduced dental arch: Concepts and updates-literature review. Dental Press Implantol. 2012;6(1):68-74

3. Guiney H, McKenna G, Whelton H, O'Mullane D. Is the shortened dental arch an underused treatment strategy in the Republic of Ireland? Community Dent Health. 2011;28(4):265-8. PMid:22320063

4. Armellini D, von Fraunhofer JA. The shortened dental arch: A review of the literature. J Prosthet Dent. 2004;92(6):531-5. PMid:15583557

5. Kayser AF, Witter DJ. Oral functional needs and its consequences for dentulous older people. Community Dent Health. 1985;2(4):285-91.

PMid:3866631

6. Käyser AF. Limited treatment goals-shortened dental arches. Periodontol. 2000 1994;4:7-14. https://doi. org/10.1111/j.1600-0757.1994.tb00001.x PMid:9673189

7. Walther W. The concept of a shortened dental arch. Int J Prosthodont. 2009;22(5):529-30.

PMid:20095215

8. WitterDJ,Allen PF, Wilson NH, KäyserAF. Dentists' attitudes to the shortened dental arch concept. J Oral Rehabil. 1997;24(2):143 7. https://doi.org/10.1046/j.1365-2842.1997.00460.x PMid:9061624

9. Korduner EK, Söderfeldt B, Bagewitz IC, Von Steyern V, Wolf E. The shortened dental arch concept from the perspective of 
Swedish general dental practitioners: A qualitative study. Swed Dent J. 2016;40(1):1-1. PMid:27464377

10. Fernandes VA, Chitre V. The shortened dental arch concept: A treatment modality for the partially dentate patient. J Indian Prosthodont Soc. 2008;8:134-9. https://doi. org/10.4103/0972-4052.49016

11. Ribeiro MT, Rosa MA, Lima RM, Vargas AM, Haddad JP, Ferreira $\mathrm{E}$, et al. Edentulism and shortened dental arch in Brazilian elderly from the national survey of oral health 2003. Rev Saude Publica. 2011;45(5):817-23. https://doi.org/10.1590/ s0034-89102011005000057

PMid:21845293

12. Käyser AF. Shortened dental arches and oral function. J Oral Rehabil. 1981;8(5):457-62. https://doi. org/10.1111/j.1365-2842.1981.tb00519.x PMid:6975361

13. Witter DJ, van Palenstein Helderman WH, Creugers NH, Käyser AF. The shortened dental arch concept and its implications for oral health care. Community Dent Oral Epidemiol. 1999;27(4):249-58. https://doi.org/10.1111/j.1600-0528.1999.tb02018.x PMid:10403084

14. Armellini DB, Heydecke G, Witter DJ, Creugers NH. Effect of removable partial dentures on oral health-related quality of life in subjects with shortened dental arches: A 2-center crosssectional study. Int J Prosthodont. 2008;21(6):524-30. https:/ doi.org/10.1016/s0022-3913(09)60115-3

PMid:19149071

15. Gerritsen AE, Witter DJ, Bronkhorst EM, Creugers NH. An observational cohort study on shortened dental arches-clinical course during a period of 27-35 years. Clin Oral Investig. 2013;17(3):859-66. https://doi.org/10.1007/s00784-012-0765-6 PMid:22744163

16. Nassani MZ, Tarakji B, Baroudi K, Sakka S. Reappraisal of the removable partial denture as a treatment option for the shortened dental arch. Eur J Dent. 2013;7(2):251-6. https://doi. org/10.4103/1305-7456.110199

PMid:24883037

17. Abdulghani AS, Elhag SB. Shortened dental arch as a solution for maxillary sinus proximity in dental implant restoration. Clin Case Rep. 2017;5(6):782-6. https://doi.org/10.1002/ccr3.923 PMid:28588810

18. Brown R. Social Psychology. New York: The Free Press; 1965. p. $549-609$

19. Kronström M. Prosthodontics and the general dentist. A study of practice profiles and prosthodontic decision making in Sweden. Swed Dent J Suppl. 1999;137:1-62 PMid:10635102

20. Allen PF, Witter DF, Wilson NH, Kayser AF. Shortened dental arch therapy: Views of consultants in restorative dentistry in the United Kingdom. J Oral Rehabil. 1996;23(7):481-5. https://doi. org/10.1111/j.1365-2842.1996.tb00883.x PMid:8814564

21. Allen PF, Witter DJ, Wilson NH. A survey of the attitudes of members of the European prosthodontic association towards the shortened dental arch concept. Eur J Prosthodont Restor Dent. 1998;6(4):165-9

PMid:10596618

22. Sarita PT, Witter DJ, Kreulen CM, Creugers NH. The shortened dental arch concept-attitudes of dentists in Tanzania. Community Dent Oral Epidemiol 2003;31(2):111-5. https://doi. org/10.1034/j.1600-0528.2003.00018.x PMid:12641591

23. Allen PF, Witter DJ, Wilson NH. The role of the shortened dental arch concept in the management of reduced dentitions. Br Dent
J. 1995;179(9):355-7. https://doi.org/10.1038/sj.bdj.4808921 PMid:7495632

24. Gotfredsen K, Walls AW. What dentition assures oral function? Clin Oral Implants Res. 2007;18 Suppl 3:34-45. https://doi. org/10.1111/j.1600-0501.2007.01436.x PMid: 17594368

25. Kanno T, Carlsson GE. A review of the shortened dental arch concept focusing on the work by the Käyser/Nijmegen group. J Oral Rehabil. 2006;33(11):850-62. https://doi. org/10.1111/j.1365-2842.2006.01625.x

\section{PMid: 17002745}

26. Khan S, Musekiwa A, Chikte UM, Omar R. Differences in functional outcomes for adult patients with prosthodontically treated and-untreated shortened dental arches: A systematic review. PLoS One. 2014;9:e101143. https://doi.org/10.1371/ journal.pone. 0101143

27. Kumar PC, George S. An assessment of prosthodontists attitudes to the shortened dental arch concept. J Interdiscip Dent. 2012;2:104-7. https://doi.org/10.4103/2229-5194.100602

28. Alammari M. Dentists attitudes regarding shortened dental arch concept in senior dental patients. Int J Dent Sci Res. 2017;5:25-30.

29. Khan SB, Omar R, Chikte UM. Perceptions regarding the shortened dental arch among dental practitioners in the Western Cape Province, South Africa. SADJ. 2012;67(2):60, 62-4, 66-8. PMid:23189894

30. Abuzar MA, Humplik AJ, Shahim N. The shortened dental arch concept: Awareness and opinion of dentists in Victoria, Australia. Aust Dent J. 2015;60(3):294-300. https://doi.org/10.1111/adj.12245 PMid:25346444

31. Gupta R, Malhi R, Patthi B, Singla A, Janakiram C, Pandita V, et al. Experience from classroom teaching to clinical practice regarding shortened dental arch (SDA) concept among dentists-a questionnaire study. J Clin Diagn Res. 2016;10(12):ZC27-32. https://doi.org/10.7860/jcdr/2016/20855.9045 PMid:28208999

32. Kasim SK, Razak IA, Yusof ZY. Knowledge, perceptions and clinical application of the shortened dental arch concept among Malaysian government dentists. Int Dent J. 2018;68(1):31-8. https://doi.org/10.1111/idj.12325

PMid:28782099

33. Vohra F, Al-Qahtani M, Momenah N, Al-Kheraif AA, Ab-Ghan SM. Knowledge and attitudes of dentists toward shortened dental arch therapy in Saudi Arabia. Niger J Clin Pract. 2016;19(3):380-5. https://doi.org/10.4103/1119-3077.179288 PMid:27022804

34. Arigbede AO, Ajayi DM, Akeredolu PA, Onyeaso CO. Attitudes and perception of Nigerian dentists about shortened dental arch therapy (SDAT). Odontostomatol Trop. 2009;32(126):13-9. PMid:20069962

35. Levey C, Dunbar C. Shortened dental arch concept shown to be cost effective. Evid Based Dent. 2015;16(1):19-20. https://doi. org/10.1038/sj.ebd.6401080 PMid:25909936

36. McKenna G, Allen F, Woods N, O'Mahony D, Cronin M, DaMata $\mathrm{C}$, et al. Cost-effectiveness of tooth replacement strategies for partially dentate elderly: A randomized controlled clinical trial. Community Dent Oral Epidemiol. 2014;42(4):36674. https://doi.org/10.1111/cdoe.12085 PMid:24251386

37. Moore C, McKenna G. In patients with shortened dental arches do removable dental prostheses improve masticatory performance? Evid Based Dent. 2016;17(4):114. https://doi. org/10.1038/sj.ebd.6401204

PMid:27980336 


\section{Appendix -1}

\section{Questionnaire Set Form}

An Assessment of Dentists' Attitudes toward the Shortened Dental Arch Concept, in the Aseer region. Saudi Arabia

Consent Letter for Survey Research

Dear Participant,

You are invited to participate in a research study (survey) being conducted by Dr. Rania A Shareef, Dr. Mohamed Fadul A. Elagib, and Dr. Saurabh Chaturvedi as staff researchers at KING KHALID UNIVERSITY, COLLEGE OF DENTISTRY, with Dr. Ghazala Suleman as the Principal Investigator. The purpose of the research is to determine: An Assessment of Dentists' Attitudes toward the Shortened Dental Arch Concept, in the Aseer region, Saudi Arabia.

The enclosed questionnaire has been designed to collect information on the attitude and knowledge about Shortened Dental Arch Concept. Approximately 300 people will participate in this study.

Your participation in this survey is completely voluntary. You may decline altogether or leave blank any questions you don't wish to answer. There are no known risks to participation. Your responses will be confidential, and data from this research will be reported only as a collective combined total. No one other than research staff will know your individual answers to this questionnaire.

If you agree to participate in this project, please SIGN this consent letter and answer the questions on the questionnaire as best you can. It should take approximately 2-3 minutes to complete. Please return the questionnaire as soon as possible to the investigator.

If you have any questions about this project, feel free to contact any of the above-mentioned researchers.

Thank you for your assistance in this important endeavor.

Participant name -

Signature \& date -

Sincerely yours,

Dr. Ghazala Suleman

\section{PRINCIPAL INVESTIGATOR}

\section{INTRODUCTION TO THE SHORTENED DENTAL ARCH CONCEPT}

The shortened dental arch concept maintains the goal of oral health as given by the WHO in 1992 of "retaining healthy functional, esthetic, natural dentition of not less than 20 teeth and not requiring recourse to prosthesis".
In the past, it was considered essential to replace all of the missing teeth, but it is not always possible to maintain the occlusion of a complete dental arch, especially in middle-aged, elderly, and high-risk patients. The concept of a minimum of 20 teeth aims at preserving the most strategic parts of the dental arches comprising the anterior and premolar teeth. The shortened dental arch concept maintains acceptable oral function, including the chewing ability and occlusal stability as well as the aesthetics of dentition. It is a simplification of holistic restorative treatment and maintenance of restorations. It enhances the prognosis for the remaining teeth. It is economically effective and a problem-oriented approach for the treatment of partially edentulous individuals.

\section{Survey \\ AN ASSESSMENT OF DENTISTS \\ ATTITUDES TOWARD THE SHORTENED DENTAL ARCH CONCEPT}

\begin{tabular}{l}
\hline General Information \\
$\begin{array}{l}\text { Gender: } \\
\text { Male } \square\end{array}$ \\
Female $\square$ \\
2. $\quad \begin{array}{l}\text { Qualification: } \\
\text { Graduate } \square\end{array}$ \\
Post graduate $\square$ \\
3. $\quad \begin{array}{l}\text { Years of experience (Teaching/Practicing) } \\
1-5 \text { years } \square\end{array}$ \\
5-10 years $\square$ \\
More than 10 years $\square$ \\
Career prospective \\
Academician $\square$ \\
Clinician $\square$ \\
Both $\square$
\end{tabular}

5. Do you know about the Shortened Dental Arch (SDA) concept?

Yes $\square$

No $\square$

If the answer to $Q 5$ is 'No', please go to question number 15

6. Where did you learn about the Shortened Dental Arch?

Undergraduate studies $\square$

Post graduate studies $\square$

Self education $\square$

Continuing education $\square$

From colleagues $\square$

Conference/Seminar $\square$

Other (Specify .......)

7. What are the clinical situations you think are most appropriate to propose SDA to patients? 


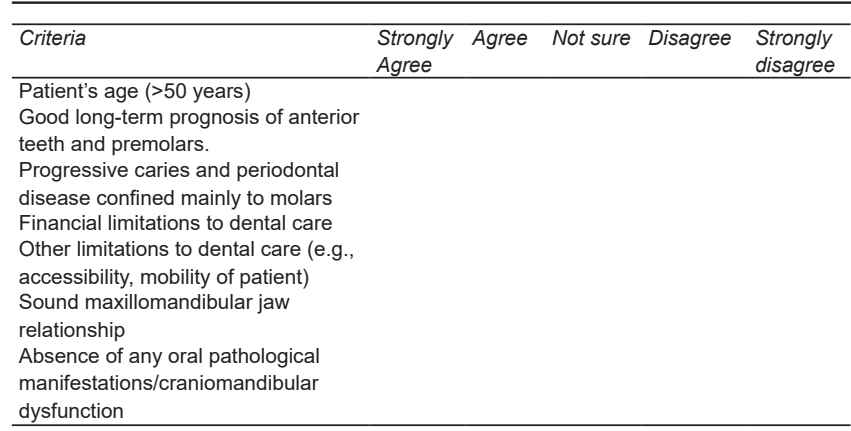

8. How often have you considered applying the SDAC in your practice?

Very Frequently $\square$

Regularly $\square$

Occasionally $\square$

Never $\square$

9. What were your patients' reactions in response to your proposal of SDA as a treatment option? Objection $\square$

Initial objection/compliance after explanation given $\square$

No objections $\square$

Cannot say $\square$

10. Do you think an individual with SDA needs further treatment?

Yes $\square$

No $\square$

Maybe $\square$

11. Do you think there is any change in masticatory efficiency with the SDA?

Yes $\square$

No $\square$

Maybe $\square$

12. Does the SDA lead to TMJ-associated issues?

Yes $\square$

No $\square$

Maybe $\square$
13. Does the cost of treatment generally influence the patients acceptance of SDA?

Yes $\square$

No $\square$

Don't know $\square$

14. In your opinion, does the SDA concept have a useful place in clinical practice?

Yes $\square$

No $\square$

Don't know $\square$

15. In your opinion, what is your response to the statement, "All missing molar teeth should be replaced in all patients"?

\begin{tabular}{|c|c|c|c|c|c|}
\hline $\begin{array}{l}\text { Strongly } \\
\text { Agree }\end{array}$ & Agree & Neutral & Disagree & $\begin{array}{l}\text { Strongly } \\
\text { disagree }\end{array}$ & Don't know \\
\hline
\end{tabular}

16. When you provide prostheses to replace missing first, second and/or third molars for older patients ( $>50$ years), what are your reasons for replacement generally? (Please check all appropriate responses)

To restore posterior support..............

Prevention of anterior wear...............

Improved masticatory function...........

For patient's desire...................

To maintain health of TMJs ................

Aesthetics ..............................

Other reasons (specify)..................

17. What percentage of the following procedures do you perform at your practice, to replace posterior teeth for older adults (>50 years)?

Removable prosthesis.

Fixed prosthesis.

Implant supported/removable/fixed

18. Any other comments

Thank you 